\title{
Institutional Factors for Supporting Electronic Learning Communities
}

\author{
Jayme N. Linton \\ Lenoir-Rhyne University
}

\begin{abstract}
This study was designed to explore how the electronic learning community (eLC) process at an established state virtual high school (SVHS) supported new and veteran online high school teachers through the communities of practice (CoP) framework. Specifically, this study focused on the institutionally-driven nature of the eLC process, using Wenger's CoP framework to analyze institutional factors that influenced the eLC process. Case study methods, including observation, interviews, and document analysis, were used to provide a rich and dynamic analysis of the eLC process in light of what research says about preparation and support for quality online teaching. While the institutionally-driven nature of the eLC process posed some barriers to alignment with the domain and community elements of the CoP framework, case study participants expressed that the eLC process impacted their practice and connected them to colleagues with which they could collaborate and problem solve. The use of strategies such as valuing the work of eLCs, removing barriers, and connecting the eLC process to the organizational strategy served to facilitate alignment with the CoP framework and overcome some of the potential disadvantages of an institutionally-driven eLC process.
\end{abstract}

Keywords: Electronic learning community, online learning community, K-12, virtual school, community of practice

Linton, J. N. (2017). Institutional factors for supporting electronic learning communities, Online Learning 21(1), 238-256. doi: 10.24059/olj.v21i1.953

\section{Introduction}

While much of what constitutes effective teaching in traditional classrooms also translates to good teaching online (Garrison \& Anderson, 2003; Journell et al., 2013), an additional set of skills and competencies is needed to ensure high levels of student engagement and student learning in virtual settings (Learn NC, 2008; NEA, 2006; Palloff \& Pratt, 2011; Redmond, 2011). These skills and qualities for teaching online courses, such as developing presence online and facilitating asynchronous discussions, are absent from teacher education programs (Barbour, Siko, Gross, \& Waddell, 2013). In some cases, this leads to K-12 administrators touting online learning as unsuccessful when, in reality, the lack of training and 
support may be what is setting up many online instructors and online learners to fail (Learn NC, 2008). Forced to fend for themselves, many online instructors have adopted a "sink or swim" mentality, taking responsibility for their own professional learning (Hawkins, Graham, \& Barbour, 2012; Marek, 2009; Ray, 2009).

This study was designed to explore how the electronic learning community (eLC) process at an established state virtual high school supported new and veteran online high school teachers through the communities of practice (CoP) framework. The institutionally-driven eLC process was designed to support online teachers through ongoing collaboration and professional development. While a research base on preparation and support for online instructors is growing, a theoretical framework is often missing in these studies. his study sought to apply the CoP framework to an institutionalized eLC process for supporting online instructors.

\section{Communities of Practice}

\section{Literature Review}

Essential to any CoP is a common domain, consisting of concepts and issues related to a body of knowledge that is necessary for members to develop their competencies and skills. The domain connects the work of the community to a broader community of practitioners. According to Wenger, McDermott, and Snyder (2002), “A shared domain creates a sense of accountability to a body of knowledge and therefore to the development of a practice” (p. 30). The second necessary element of a CoP, according to Wenger (1998), is a community of people who "interact, learn together, build relationships, and in the process develop a sense of belonging and mutual engagement” (Wenger et al., 2002, p. 33). Community within a CoP involves sustained, community-building engagement among members and a shared repertoire of strategies, tools, routines, and language as they engage in joint enterprise with other members. In addition to a community of members committed to a common domain, Wenger's (1998) CoP framework includes the element of practice, which is defined as "doing in a historical and social context that gives structure and meaning to what we do" (Wenger, 1998, p. 46). In other words, practice is the "doing” of a CoP. Wenger's (1998) concept of practice can be examined through the ways in which community members explore and produce ideas together.

The relationship between a CoP and the organization in which members work can range from unrecognized by the organization to highly institutionalized (Wenger et al., 2002). While the health of CoPs "depends primarily on the voluntary engagement of their members and on the emergence of internal leadership" (Wenger et al., 2002, p. 11), organizations can foster the growth and development of CoPs by valuing their work, creating time and space for CoP tasks, encouraging participation, and removing barriers (Wenger et al., 2002). In fact, successful CoPs which are likely to inspire growth, leadership, and innovation exist at the intersection of "strategic relevance" to the organization and the passions of community members (Wenger et al., 2002, p. 31).

Wenger et al. (2002) suggested that "without intentional cultivation, the communities that do develop will depend on the spare time of members" (p. 13). As CoPs address complex issues, solve problems, and contribute to improved practice, they offer value to the organization, measurable by both tangible results (i.e., improved skills and faster access to information) and intangible results (i.e., relationships, confidence, and a sense of belonging) (Wenger et al., 2002). 
Perhaps of primary importance, CoPs bring value to the organization by "connecting the personal development and professional identities of practitioners to the strategy of the organization" (Wenger et al., 2002, p. 17). Whether a CoP is initiated by members or an organization, the ultimate success of the community will depend on the energy which members of the community generate (Wenger et al., 2002).

Communities of practice can exist along a continuum from unrecognized by the institution to highly institutionalized. The eLC process selected for this case study was institutionalized in that it was conceived and structured by state virtual high school (SVHS) leadership and mandated for teachers. While the success of a CoP is dependent upon the engagement of members (Wenger et al., 2002), organizations can support and increase the effectiveness of the work of CoPs in five ways: value the work of eLCs, create time and space, encourage participation, remove barriers, and connect to the organizational strategy. These five organizational strategies were examined during this case study to explore ways in which the eLC process supported new and veteran online teachers.

\section{Electronic Learning Communities}

An electronic learning community is defined as an online space to which members are committed and involved professionally over an extended period of time, with opportunities for synchronous and asynchronous communication (Duncan-Howell, 2010). Electronic learning communities create a third space for participants, where learners and experts are equals in the knowledge building process (So, Loss, Lim, \& Jacobson, 2009). Participants use this third space to discuss common interests. According to an online survey of 98 members of three online communities for teachers, participants joined those communities to learn from their peers, keep up-to-date with current trends, engage in discussions, share professional knowledge, obtain support from colleagues, and build a safety net of like-minded educators. Approximately $87 \%$ of those survey respondents felt their online communities were meaningful. Seventy-seven percent reported that they made changes to their teaching practices as a result of their participation in an electronic learning community (Duncan-Howell, 2010).

By moving an existing professional learning community (PLC) into an online environment, K-12 teachers can extend their collaboration outside of their work day and transcend geographical boundaries (Tsai, Laffey, \& Hanuscin, 2010). The Internet also can facilitate relationships within local communities of learners by providing them with a set of learning and collaboration tools that can be tailored to meet the needs of the community (Clary \& Wandersee, 2009; Schlager \& Fusco, 2003). Online environments that support existing schoolbased learning communities allow community members to take on leadership roles within different contexts (Schlager \& Fusco, 2003). Results from a recent mixed-methods study revealed that teacher teams functioned well when using an online space to strengthen their existing learning communities (Parr \& Ward, 2006). These teachers, first and foremost, felt safe within their existing learning community first, which contributed to the success of their online community. Parr and Ward (2006) also found that the existence of a well-functioning PLC within a school increased the likelihood that teachers would find success in an online learning community. Similarly, K-12 teachers involved in online professional development reported that their participation in an online discussion board reinforced the learning that had taken place among colleagues within the same school (Signer, 2008). Data gathered by Holmes, Signer, and 
MacLeod (2010) showed that social presence was the greatest factor influencing teachers' learning and satisfaction online. When an existing PLC moved into an online environment, the social presence of the group contributed to the group's online learning.

\section{Components of Electronic Learning Communities}

Building an electronic learning community requires that community members combine technology and procedures that facilitate collaborative learning (Yeh, 2010b). Technology integration can support and motivate teachers to focus on continuous growth and school improvement (Williams, Atkinson, Cate, \& O'Hair, 2008). Factors that influence the success of electronic learning communities include motivation to participate, a sense of group trust, cooperation, sociability, and usability. Similarity among group members also contributed to the belongingness felt by members of an electronic learning community (Yeh, 2010b). Rovai (2001) conducted a mixed-methods study of adult learners interested in distance learning. He described four dimensions that build a sense of community online: spirit, trust, interaction, and learning. Yeh (2010a) identified four types of electronic learning communities by analyzing discussion board messages: active collaboration, passive collaboration, individualized participation, and indifference. The active collaboration communities, which consisted of high levels of member participation and collaboration, performed best in assigned tasks online.

In a study of 32 pre-service teachers participating in a blended learning environment, composed of online and face-to-face learning experiences, Yeh (2010b) identified four stages for building an online learning community. Teachers moved through the stages of motivation and acquaintance, socialization and belongingness, information exchange and consensus, and tacit understanding and development. Electronic learning community members working at the highest stage of Yeh's model communicated well with one another and achieved goals effectively. A similar model developed by Waltonen-Moore, Stuart, Newton, Oswald, and Varonis (2006) included five stages of online group development: introduction, identification, interaction, involvement, and inquiry. The final stage, inquiry, occurred when teachers put what they learned into practice. Online communities who reached the inquiry stage behaved in ways similar to face to face conversations, with a lot of give and take among community members.

\section{Benefits of Electronic Learning Communities}

Taking advantage of electronic learning communities can provide numerous benefits to K-12 teachers. However, before teachers can benefit from an online learning community, they must first perceive a need and recognize that an online community can be a solution to address that need (Parr \& Ward, 2006). Teachers involved in electronic learning communities have increased access to resources and flexibility with regard to the time and place in which they work (Lock, 2006). Learning in an online community has been described as immediate, relevant, authentic, and linked to real life as teachers directed their own discovery and construction of knowledge (Duncan-Howell, 2010). As opposed to expert-directed professional development, online communities can build teachers' capacity by giving them ownership of their own learning (Lock, 2006). For example, teachers participating in the online course studied by Holmes et al. (2010) reported that their online learning community provided them with a variety of instructional strategies. The access to resources afforded them by the electronic learning community impacted their teaching practice. In addition, online learning communities offered teachers a common language for communicating about teaching and learning (Chen, Chen, \& 
Tsai, 2009). Chen et al. (2009) further found that the use of technology as a tool to develop PLCs contributed directly to instructional practices. Their data also showed that technology made teacher collaboration faster and simpler.

\section{Challenges of Electronic Learning Communities}

While providing numerous benefits for $\mathrm{K}-12$ teachers, online learning environments can pose several challenges as well. Duncan-Howell (2010) conducted an online survey of 98 teacher members of an electronic learning community. Participating teachers self-reported that time management and sidetracked conversations were barriers to effective learning online. Teachers involved in online professional development identified personal technological preferences, such as familiarity or comfort with specific types of software or web programs, as the basis for most problems within the online learning environment (Clary \& Wandersee, 2009). Chen et al. (2009) also identified technical expertise as a factor in building a successful online learning experience for teachers. Similarly, Holmes et al. (2010) found that teachers with prior online learning experience were more satisfied with online professional development courses.

In her literature review of online teacher communities in K-12 education, Lock (2006) summarized the reasons why many electronic learning communities have failed, including problems with technology, lack of time, learner readiness, mismatch to the school culture, and quality of the community. The success of an electronic learning community is partly dependent on the technology available to facilitate teacher learning online. Technology tools used to support the online community should be flexible and meet the needs of community members. Lock (2006) also pointed out that online communities failed when teachers were not ready to participate. They must be self-motivated and independent learners and have a level of confidence with technology use. Effective online communities require teachers to transition from an isolated, autonomous working environment to one that is collaborative, but school culture can hinder the effectiveness of electronic learning communities. If a school's culture does not foster collaboration and collective learning, it can be difficult for teachers to break free from the traditional school culture of independence and autonomy. In addition, the electronic learning community should be integrated into teachers' professional development practices rather than being perceived as an add-on. "The power and direction of the community must come from community members. It cannot be imposed on them,” (Lock, 2006, p. 673).

A large case study was conducted to explore several facets of the eLC process through the lens of the CoP framework. Specifically, the findings presented here focused on the institutionally-driven nature of the eLC process, using Wenger's (1998) CoP framework to analyze institutional factors that influenced the eLC process. Other aspects of Wenger's CoP framework are beyond the intended scope of this article. Case study methods, including observation, interviews, and document analysis, were used to provide a rich and dynamic analysis of the eLC process in light of what research says about preparation and support for quality online teaching. This case study was designed to examine data gathered through the eLC process at SVHS in order to address the following research question: In what ways do institutionally-driven electronic learning communities operate like communities of practice from the perspective of experienced online teachers, novice online teachers, and learning community leaders? 


\section{Methods}

\section{Setting and Sample}

The second largest state virtual school in the country, referred to in this study as the State Virtual High School (SVHS), was commissioned in 2005 to provide e-learning opportunities to high school students from across a state in the southeastern United States. Courses for students were first offered in the summer of 2007. During its first year, 17,325 students enrolled in courses through SVHS. During the 2014-15 school year, SVHS enrolled 71,932 students in grades six through 12, with a total of 111,634 course enrollments (Watson et al., 2015). During the 2012-13 school year, SVHS contracted with nearly 700 online teachers who provided instruction to students from all 115 school districts in the state as well as 44 charter schools.

Virtual teachers at SVHS must first complete an 18-week induction program, which is designed to orient teachers to SVHS expectations as well as strategies and tools for effective online teaching. The induction program consists of a nine-week orientation to online teaching and a nine-week practicum which allows SVHS teaching candidates to apply online teaching skills by co-teaching online courses with veteran SVHS teachers. The first nine weeks orient candidates to online teaching competencies and to the expectations for online teaching at SVHS. Topics include instructional design models, expectations for communication with SVHS students and parents, web tools, copyright, and reporting student progress, among others. These expectations are presented synchronously and asynchronously by the orientation leader and veteran SVHS teachers. All candidates must attend synchronous sessions, participate in asynchronous discussion, and complete assignments each week. These synchronous and asynchronous experiences require SVHS teaching candidates to reflect on and apply course content.

Following the nine-week orientation, teaching candidates are matched with veteran SVHS teachers for a nine-week practicum experience. Each candidate takes on gradual responsibility, with mentorship and supervision by the veteran teacher, for online teaching in a course within his or her content area. Responsibilities taken on by SVHS candidates include maintaining regular communication with students and their parents, posting announcements, grading and providing feedback on student work, and reporting student progress to local school districts. Upon successful completion of the orientation, which is measured by weekly active participation in synchronous meetings and asynchronous discussions and multiple opportunities to apply and demonstrate online teaching skills through assignment submission, SVHS teachers become members of course-specific electronic learning communities. Within eLCs, teachers work collaboratively both synchronously and asynchronously to carry out their work as virtual teachers. This work includes course revision, sharing effective teaching practices, and goalsetting and reflection. During the virtual practicum, each candidate joins the eLC to which his or her mentor teacher belongs.

Electronic learning communities (eLCs) function as part of the overall continuous professional learning program for SVHS teachers. All SVHS teachers are contractually obligated to participate in the eLC process, which is designed to facilitate professional learning, collaboration, and growth among SVHS teachers. Other professional learning opportunities are offered to SVHS teachers on an as-needed basis, including a recent self-paced online training on 
a new learning management system. According to the SVHS chief academic officer, the purpose of eLCs is to provide a collaborative process for teachers to enhance their practice and improve student learning.

Electronic learning communities are organized by program of study and content area. Programs offered by teachers at SVHS include the following: traditional program of study, credit recovery, occupational course of study, and STEM (science, technology, engineering, and math). Within this structure, all SVHS teachers belong to a course-specific eLC. For example, all SVHS teachers who teach sections of Biology belong to the Biology eLC. Further, with traditional courses that have high enrollment, such as psychology, teachers of the general and honors sections function as separate eLCs. That is, all teachers of the general psychology course belong to the psychology eLC, while all teachers of the honors psychology course belong to the honors psychology eLC. This qualitative case study focused on the eLC process for online English teachers during the spring of 2014.

The total sample for this study included seven female SVHS employees, six of whom taught high school English, and the chief academic officer for SVHS. Two participants were new online teachers, having taught for SVHS for one year or less; two were classified as veteran online teachers, having taught for SVHS for three years or more; and two were eLC facilitators who were responsible for leading the eLC process for their respective courses. Institutional Review Board approval was obtained from the researcher's institution and SVHS.

\section{Data Collection and Analysis}

The institutionally-driven eLC process at SVHS was selected for this case study. Case study data were gathered over twelve weeks via interview, observation, and the collection of documents and shared websites. Three eLCs within the English department were selected by the SVHS research coordinator, who selects participants for and coordinates all external research, for observations and document analysis. Observations were conducted during seven monthly synchronous online eLC meetings that were hosted by each eLC facilitator within the learning management system. Shared documents, such as collaboratively constructed formative assessments, archives of announcements, and reflections to monthly eLC questions distributed by the chief academic officer, used by eLC participants for ongoing asynchronous eLC participation were collected and analyzed, along with eLCCommunication via email. Further, seven eLC participants, all female, were interviewed, including the chief academic officer, two instructional leaders, two veteran teachers, and two new teachers at SVHS. The following interview questions were used to guide one semi-structured interview with each of the seven participants.

1. Tell me about your experience as an online teacher (or instructional leader or chief academic officer) for SVHS and a member (or facilitator) of an eLC.

2. How is the eLC process structured at SVHS?

3. Have you participated in a face-to-face learning community? If so, how is participation in the eLC similar to or different from participation in a face-to-face learning community?

4. What are the areas of focus of your eLC?

5. What types of support are available to you through membership in the eLC?

6. What is expected of you as an eLC member (or facilitator)? 
7. How do you participate in the eLC? In what ways are you involved?

8. What expectations do eLC members have of each other?

9. How do you communicate with other members of your eLC?

10. What kinds of relationships have you developed with other members? How have those relationships changed over time?

11. How would you say your own practice has changed, or not, as a result of being a member of an eLC?

Interview participants varied widely in their teaching experience, ranging from seven to 32 years of traditional face-to-face teaching and from one semester to eight years of online teaching. Pseudonyms are used to protect the identities of participants. See Table 1 for participant demographic information.

Table 1

Electronic Learning Community Member Demographics

\begin{tabular}{lccc}
\hline & Mean & $\begin{array}{c}\text { Standard } \\
\text { Deviation }\end{array}$ & Range \\
\hline Age in Years & 42 & 8.50 & 27 \\
Years of Face-to-Face Teaching Experience & 16 & 9.18 & 27 \\
Years of Online Teaching Experience & 4.48 & 2.79 & 7.33 \\
Total Years of Teaching Experience & 17 & 7.81 & 24 \\
\hline
\end{tabular}

While drawing the sample from a diverse group of eLCs from different disciplines was preferred, the research coordinator for SVHS selected the eLCs and participants for the study due to the amount of SVHS teacher participation in other research studies. With multiple studies occurring at SVHS during the spring 2014 semester, the SVHS research coordinator selected the six teacher participants and English eLCs involved in this case study. This poses a limitation to this study, since these participants may not be representative of the rest of the population of SVHS teachers and leaders in other disciplines or other eLCs. Further, while this case study provides a glimpse into the nature of the eLC process, twelve weeks is not enough time to truly determine alignment with the $\mathrm{CoP}$ framework. In order to better understand the institutional factors that supported the eLC process for online teachers, more time for data collection would be needed.

All data were analyzed using NVivo, a qualitative data analysis software to explore relationships and identify trends (Richards, 1999), through Wenger's (1998) CoP framework and were coded according to five organizational strategies identified by Wenger et al. (2002) as techniques for supporting communities of practice. Data analysis software was used to organize and code each piece of data collected. For example, phrases from interviews were tagged according to the five organizational strategies for supporting CoPs, as were responses to eLC reflection questions in shared documents, comments made during synchronous eLC meetings, and emails. Prior to data collection, the researcher generated possible examples of data to represent each code. This coding structure was used to analyze shared documents, field notes 
collected during synchronous observations, transcripts from interviews, and emails among eLC members.

\section{Findings}

\section{Introduction}

According to five of the seven interview participants, the eLC process has improved since its inception in 2010. Amy described that "over the years the eLCs have become much more valuable and meaningful (Amy, personal communication, February 26, 2014)." Similarly, Simone referred to the eLC process during an interview as "a gradual improvement. It gets better every year (Simone, personal communication, March 9, 2014).” Tina, a course lead, described how this improvement has occurred, saying, "They were always asking, 'Is this helpful? How can we make this better?' And they listened. And they still do that. Like I said, we're ever changing the courses, we're always trying to improve. They're very responsive (Tina, personal communication, February 26, 2014)."

Donna agreed, "We've gotten better at it year by year as we really look at what works and what doesn't work (Donna, personal communication, February 26, 2014)." She stated that during the spring of 2014, she was, "the happiest I've ever been, last semester and this semester, with what the eLCs look like." She went on to say, "I think we're getting there. I think we have a ways to go, but I think we are doing it the best this semester than we have ever done it, and that is simply because of trial-and-error (Donna, personal communication, February 26, 2014).”

Findings below, organized and coded according to strategies recommended by Wenger et al. (2002), revealed efforts made by SVHS to foster the growth and development of the eLC process.

\section{Value the Work of eLCs}

Repeatedly, in weekly reflections, emails, and synchronous meetings, eLC members were thanked for their work. During a live English I eLC meeting, Donna, the chief academic officer, expressed her gratitude, "You guys have been fantastic at how you have approached it in your eLCs. We cannot thank you enough for analyzing student work in such a proactive way (Donna, eLC meeting, March 27, 2014).” During another synchronous English meeting, Donna told teachers, "I appreciate what you guys do so much (Donna, department meeting, March 17, 2014)." This sentiment was also regularly expressed within instructions for weekly reflections, which often concluded with a statement such as, "Thank you for your work this week (Donna, eLC newsletter, March 2014)!” Donna expressed that it was important to her to ensure that teachers felt their time was honored. "I never want the teachers to feel like their time has been wasted (Donna, personal communication, February 26, 2014).” A veteran teacher and course lead, Tina expressed that she "always appreciated being treated like a professional by [SVHS]. I always feel like they appreciate me (Tina, personal communication, February 26, 2014).”

In addition to expressions of gratitude, SVHS demonstrated that it valued eLC work in other ways. For instance, synchronous meetings often included celebrations, both personal and professional, and recognition of effective practices used by SVHS teachers. Further, SVHS regularly gathered feedback from eLC members and used that feedback to make adjustments to the eLC process. During a synchronous meeting, all honors teachers were asked provide 
feedback on what was working well with the eLC process as well as suggestions for improvement. As previously shared by Tina, SVHS frequently asked, “'Is this helpful? How can we make this better?' And they listened. And they still do (Tina, personal communication, February 26, 2014).”

\section{Create Time and Space}

The eLC structure, with weekly asynchronous work via reflection questions and monthly synchronous meetings, provided consistent, focused time and space for eLC work to happen. While Wendy felt that she did not typically like that type of structure all time, she believed that "it works in this situation, because it keeps us on track and it keeps us talking about what we're supposed to be talking about (Wendy, personal communication, March 12, 2014).” Instructional leader Simone also appreciated the structure of the eLC process, which allowed teachers to review shared practice from previous months. According to Simone, compared to face-to-face learning community work, the eLC structure was "more accessible. It's more permanent (Simone, personal communication, March 9, 2014).”

In addition to the structure of time and space for ongoing eLC work, SVHS worked to provide important content in an easily digestible format. Specifically, the honors portfolio process was broken down into small chunks of information and specific steps for eLCs to complete. In an email to the English I eLC, Amy explained that Donna had "broken it down really carefully for us and we are to move through it one week at a time (Amy, eLC meeting, February 24, 2014)." Later, during a synchronous meeting, she stated that Donna had "laid out a document to walk teams through the portfolio week-by-week (Amy, eLC meeting, February 24, 2014).” Also, Advanced Placement ${ }^{\oplus}\left(\mathrm{AP}^{\circledast}\right)$ data were presented in an organized, condensed format for $\mathrm{AP}{ }^{\oplus}$ teachers to use during their eLC work. The presentation of weekly and monthly information related to the eLC focus in a consistent and structured format provided evidence that SVHS created time and space for ongoing eLC work.

\section{Encourage Participation}

Since regular and active participation in the eLC process was an expectation of all SVHS teachers enforced through the teacher evaluation process, participation was not voluntary. However, the levels at which members participated and contributed to both the eLC process and the organization varied. Further, eLC members were encouraged to participate at different levels of engagement. In interviews, course leads and instructional leaders described being approached by SVHS leaders and asked to assume leadership roles within the eLC process. These leaders were then provided professional development and support as they moved into leadership roles. The selection and preparation of eLC members to take on core leadership roles within the eLC process encouraged different levels of participation. In addition to course lead and instructional leader roles, eLC members were also provided additional opportunities to participate via minicontracts for course revision. Donna explained that mini-contracts would be used to complete course revisions at the end of the honors portfolio process. Teachers expressed appreciation that mini-contracts would be used for course revision to honor teachers’ time in the eLC process.

According to Wenger et al. (2002), maintaining small community sizes is one technique for encouraging all members to participate actively. Each eLC participating in this case study had either two, three, or four community members. Within these small communities, each 
member was encouraged and expected to contribute to synchronous and asynchronous eLC work. Other data coded as "encourage participation" included reminders and prompts to participate from eLC leaders. For instance, Amy emailed level I English teachers, "If you haven't completed week 1 yet please go ahead and do so - it was due yesterday (Amy, email, March 3, 2014)." Amy described her efforts to encourage participation within synchronous meetings, particularly with one eLC that was a "really quiet group" as "pulling teeth (Amy, personal communication, February 26, 2014)." On the contrary, the other eLC in which Amy participated was very talkative and participatory. Donna also encouraged participation during synchronous meetings, as evidenced during a previously described synchronous meeting when she asked participants to be active in the conversation and avoid multi-tasking. She communicated to meeting participants that she expected them to be active in the chat.

\section{Remove Barriers}

Within the SVHS eLC process, some data revealed that distance presented a barrier to community development, while other data showed that distance was not a barrier. According to instructional leader Amy, some eLCs used online tools such as Skype and Google Hangouts to foster community development. In this way, eLC members were able to see and hear each other and, in addition, they got to know each other's families. Other communities were described by Amy as being more "business-like (Amy, personal communication, February 26, 2014).” New teacher Cheryl described that she was able to meet some of her fellow eLC members, who lived close to her, face-to-face for breakfast. She added that she was not able to meet other eLC members due to the distance between them.

Some evidence of distance posing a barrier within the eLC process was found in asynchronous work. Although eLCs participated in monthly synchronous meetings, the majority of eLC work occurred asynchronously. Members were required to post responses to weekly reflection questions then return later to the document to read one another's responses. Instructions for eLC work typically included a statement such as this one, "Wait a few days and come back to this document and read through your team's responses (Weekly reflection, January 27, 2014)." In a face-to-face community, this discussion would take place synchronously, with community members engaging in natural dialogue, commenting on one another's thoughts, and contributing in real-time. The delayed response via asynchronous discussions added wait time to eLC conversations.

Contrasting evidence was found, supporting the notion that distance did not present a barrier to participation in the eLC process. In fact, eLC members felt that the electronic nature of the eLC process facilitated participation. Tina described that "sharing is so easy on the computer with Google Docs to actually copy / paste precisely what you did (Tina, personal communication, February 26, 2014)." SVHS worked to remove barriers created by distance through the provision of frequent opportunities for interaction among eLC members. In contrast to Wenger et al. (2002), eLC members were not likely to forget that the community existed, as participation was mandatory and both structures and resources were provided to facilitate active participation among all members. Participation within the joint enterprise of the eLC was an ongoing part of work as an online teacher for SVHS, and communication within the eLC process was frequent, occurring via email, phone, synchronous meetings, and shared documents. 
Specific strategies were employed by SVHS to remove potential barriers to participation in the eLC process. For example, all synchronous meetings were archived and posted to the shared community space. This allowed all members to participate in synchronous meetings even when scheduling conflicts occurred. Also, as described by instructional leader Amy, weekly asynchronous work was broken down and organized in a way that made it manageable and easy to follow. The English III eLC leader emailed eLC members, "Because this is so nicely broken down for us, I think it will be manageable, especially working together (Amy, email, March 3, 2014).”

\section{Connect to the Organizational Strategy}

One way in which SVHS connected the eLC process to the organizational strategy was by determining the focus of monthly eLC work. Donna described that the eLC focus was driven by monthly results from the eLC process, with the goal of designing eLC experiences that "can be applied right now to improve student learning (Donna, personal communication, February 26, 2014).” The SVHS leadership team used the eLC process to engage teachers in work around critical issues related to the organization, which during the spring of 2014 consisted primarily of focusing on the honors portfolio process and AP» data.

For the first time in the history of the eLC process, AP ${ }^{\circledR}$ eLCs were provided with a different topic for their work than non- AP ${ }^{\star}$ eLCs during the spring of 2014. This work focused on $\mathrm{AP}^{\circledast}$ data and the culture of $\mathrm{AP}^{\oplus}$ courses at SVHS. Simone, the instructional leader for $\mathrm{AP}{ }$ English Language, explained that in her time at SVHS, she had "never known AP ${ }$ to have its own PD, so this has been really nice (Simone, personal communication, March 9, 2014).” In an

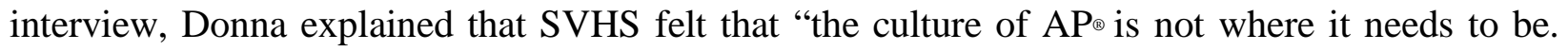
It's not reflective of the rest of [SVHS] (Donna, personal communication, February 26, 2014)." The differentiated focus for honors, AP ${ }^{\oplus}$, and other eLCs during the spring of 2014 provided evidence of the eLC process being used to target specific components of the SVHS organizational strategy.

All SVHS teachers were required to actively participate in the eLC process, which was included in the teacher evaluation structure at SVHS and part of the SVHS teacher contract. Connecting eLC participation to teacher evaluation ensured that SVHS could extend its organizational priorities and expectations to every SVHS teacher in a systematic way. As described by Donna, SVHS "incorporated it that fall into the teacher contract so they would know we were serious about it, that we expected eLCs to be a requirement weekly (Donna, personal communication, February 26, 2014)." She later added, "I think that the eLC process puts feet to our expectations, and I think it also shows the reinforcement and the support we're going to provide (Donna, personal communication, February 26, 2014),” further revealing the strong connection between the eLC process and the SVHS organizational strategy.

\section{Discussion}

To answer this study's research question, data were gathered related to five strategies identified by Wenger et al. (2002) as ways for an organization to support and increase the effectiveness of the work of CoPs: value the work of eLCs, create time and space, encourage participation, remove barriers, and connect to the organizational strategy. Findings revealed that 
these strategies did, in fact, support and increase the effectiveness of the eLC process in many ways. However, findings also revealed that the institutionally-driven nature of the eLC process also posed a barrier to the alignment of the eLC process with the CoP framework.

Wenger et al. (2002) emphasized the notion of reciprocity within the CoP framework. Individual CoP members should benefit from membership in the community, while the community also benefits from the contributions of individual members. On a larger scale, the organization should benefit from CoPs, while communities should benefit from the process as well. In this case study, the eLC process brought value to all three levels - individual, community, and organization. As described previously, teachers expressed ways their teaching improved due to participation in the eLC process. Case study participants also described finding value in relationships built through the eLC process. Just as teachers benefited from participation in the eLC process, the communities themselves were enhanced through the eLC process. The contributions of each eLC member led to the improvement of courses, and ongoing interactions among community members strengthened the community and practice of the eLCs. Further, the eLC process brought value to the organization.

Wenger et al. (2002) described that successful CoPs existed at the intersection of "strategic relevance" to the organization and the passions of CoP members (p. 31). Truman (2004) described ways in which an institutionalized support system for online faculty can be successful for instructors and the organization. In the case of the honors portfolio process, in particular, the eLC process did exist at the intersection of the needs of SVHS and the ongoing interest of eLC members in improving their practice and their courses to meet the needs of students. At a broader level, the intersection of organizational relevance and eLC members' passions existed in a focus on students. Chief academic officer Donna described the purpose of the eLC process as "our ability to be collaborative among teachers to improve student learning (Donna, personal communication, February 26, 2014).” Case study participants, including teachers and eLC leaders, also described student learning as a focus of the eLC process. Findings revealed that students were the major focus of the eLC process, with the word student(s) being the most frequently used word across all data sources as revealed by frequency counts conducted in NVivo. The eLC process, then, provided a way for teachers to collaborate and improve their teaching and their courses in the interest of increasing student learning. Organizational competence, particularly with teaching practice and student learning, was increased through the eLC process.

One way in which the institutionally-driven nature of the eLC process posed a barrier to alignment with the CoP process was related to mandatory participation. Wenger et al. (2002) argued that participation within a CoP could be mandatory, but the level of participation must be voluntary. Further, Parr and Ward (2006) found that teachers must first perceive a need, and then recognize that an electronic learning community can be a solution to that need. In the case of the SVHS eLC process, curriculum leaders at SVHS perceived a need and believed that the eLC process would meet that need. Chief academic officer Donna described in an interview that curriculum and instruction leaders were discussing ways to get teachers to collaborate with one another to address low pass rates in their courses. According to Donna, "we decided, well we know that PLCs have a great purpose behind them, so let's do an eLC (Donna, personal communication, February 26, 2014)." She further explained, "So that was how the eLCs came to 
be, out of a desperate need to have teachers collaborate and talk with each other" (Donna, personal communication, February 26, 2014). While the leadership of SVHS recognized this need and believed strongly that eLCs were the solution, it is difficult to say whether teachers themselves perceived this need and believed in the eLC process as a way to meet that need. Previous research has shown that online instructors desire community and opportunities for collaboration with other online instructors, suggesting that SVHS teachers may have recognized the same need (Terosky \& Heasley, 2015).

Lock (2006) found that eLCs can build capacity by giving teachers ownership of their learning. Lock also argued that the power and direction of eLCs comes from members. The institutionally-driven nature of the eLC process leads to questions regarding who owns and directs the learning. Aside from the month when eLCs were allowed to choose their own focus, the topics and issues addressed through the eLC process were selected by the curriculum and instruction leadership team. Although chief academic officer Donna explained that the leadership team selected topics based on the current needs of SVHS teachers and students, the argument can be made that the institutionally-driven nature of the eLC process prevented teachers from owning and directing their learning. What follows are recommendations for organizations and researchers based on findings from this case study.

\section{Recommendations for Organizations Implementing eLCs}

Provide opportunities for connecting the eLC process with professional organizations and professional learning opportunities outside of the organization. This could include providing funding for attendance at regional and national conferences, purchasing subscriptions to print or online publications, and providing access to online resources made available via professional organizations.

Implement a mentor program to support new online teachers. The mentor program can serve as a supplement to the eLC process by matching new online teachers with veteran online teachers. Mentees should be given regular opportunities to interact with their mentors, synchronously and asynchronously. The mentor program can provide new online teachers a safe space to ask questions, seek information, and gain confidence in their own practice.

Build a culture of celebration. To overcome barriers due to separations in distance and time, community-building must be an intentional component of the eLC process. Professional learning opportunities could be provided to help eLC facilitators develop skills and processes for community-building within the eLC process. Further, during organization-wide synchronous and asynchronous interactions, organization leaders can model community-building efforts.

Use a framework to guide and evaluate the eLC process. Organization leaders can collaborate to select and adapt a framework, such as the communities of practice framework, in order to ensure a consistent and systematic approach to the eLC process across the organization. Each organization should adapt the selected framework to meet the specific professional learning needs of its teachers. The revised framework can then be used to monitor and evaluate eLC implementation. 


\section{Recommendations for Researchers}

Findings and limitations from this case study led to several recommendations for researchers interested in exploring electronic learning communities. These recommendations include: 1) ground research in a theoretical framework; 2) determine effective teaching practices in online environments; 3) determine effective practices for preparing and supporting online instructors; 4) use design research to improve educational practice; and 5) explore the impact of eLC participation on online teaching practice. Each of these recommendations is described in more detail below.

First, the use of the CoP framework served to ground this study in research and provided a useful structure for organizing and analyzing data. Researchers are encouraged to use a theoretical framework as the foundation of future studies exploring eLCs, utilizing the framework to design research questions, structure the data collection process, create processes for data analysis, and interpret findings.

Furthermore, in order to support K-12 online instructors in using best practices and supporting student learning, researchers need to determine effective practices for training and supporting K-12 online instructors. Research into effective online instructional practices is expanding at a rapid rate, but research into effective models for K-12 online instructor preparation and support is still greatly needed. Teacher education programs are failing to prepare pre-service teachers for their potential future work as online teachers (Barbour et al., 2013; Journell et al., 2013; NEA, 2006).

Perhaps more important than the content of future research is the design, implementation, and reporting of this research (Barbour, 2010). According to a review of the research on K-12 online learning conducted by Barbour (2010), most current literature in the field of K-12 online education has been based on personal experiences rather than systematic research. One of the leading researchers in the field, Michael Barbour (2010) recommended that researchers use a design research approach to conduct research in K-12 online education settings. The purpose of design research is to improve educational practice through a cycle of analysis, design, development, and implementation conducted collaboratively among researchers and practitioners in authentic settings. In contrast to traditional research, the goal of design research is not to generalize findings to other settings but to collaborate with members of the research site to solve their problems (Barbour, 2010). Design research is a methodology that is systematic yet flexible enough to be practical for dynamic K-12 online environments.

Finally, one important issue that was not explored in this case study was the impact of online teachers' participation in the eLC process on their teaching. Future research could explore the impact of eLC participation on online teaching practice, providing insight for eLC leaders and teachers. A study such as this would require the researchers to dig deeper than the eLC process, gaining access to courses and students. To best explore the impact of eLC participation on online teachers' practice, a longitudinal study would be useful. Research could observe eLC participation and online teaching practice over time, exploring the relationship between the two. 


\section{Conclusion}

Case study participants described previous professional development experiences, including face-to-face learning communities, as segmented, unproductive, and disconnected from students. On the contrary, the eLC process was described by these teachers as authentic, genuine, accessible, and student-centered. For these teachers, the eLC process served as ongoing, productive professional learning that was focused on improving teaching to increase student learning. While the institutionally-driven nature of the eLC process posed some barriers to alignment with the domain and community elements of the CoP framework, case study participants expressed that the eLC process impacted their practice and connected them to colleagues with which they could collaborate and problem solve. Case study participants repeatedly mentioned that improving teaching practices and increasing student learning outcomes were desired results of participating in the eLC process. Requiring mandatory participation in the eLC process served to support SVHS teachers and students while also supporting the overall organization. Had SVHS not mandated participation in the eLC process and provided a consistent structure for ongoing eLC work, it could be argued that the beliefs and practices of these online teachers, particularly the new online teachers, would have been very different.

Further, the institutionally-driven nature also allowed the eLC process to concurrently offer value to the organization itself. The argument can be made that the supports provided the eLC process by SVHS, which were recommended by Wenger et al. (2002), allowed the institutionally-driven nature of the eLC process to act in more positive than negative ways in regards to the CoP framework. That is, the use of strategies such as valuing the work of eLCs, removing barriers, and connecting the eLC process to the organizational strategy served to facilitate alignment with the $\mathrm{CoP}$ framework and overcome some of the potential disadvantages of an institutionally-driven eLC process. Therefore, it is recommended that organizations follow guidelines from Wenger et al. (2002) to provide support for eLCs, including valuing the work of eLCs, creating time and space, removing barriers, encouraging participation, and connecting the eLCs to the organization's strategy.

Historically, SVHS curriculum and instruction leaders selected topics for the monthly eLC focus. However, during the spring of 2014, eLCs were allowed to select their own topics for one month of eLC work. This proved to be a decision that tightened the alignment of the eLC process with the CoP framework by allowing eLCs to direct and own their learning. Findings revealed that when eLCs were allowed to choose their own topics, each eLC engaged in work that was aligned to the overall focus of the eLC process and the organizational strategy. If SVHS were to continue to provide regular opportunities for eLCs to direct their own work, it would follow that this pattern would continue, maintaining connections between the eLC process and the organizational strategy while allowing each eLC to be a true CoP, in which the work of each community exists at the intersection of the goals of the organization and the passions of its members. 


\section{References}

Barbour, M. K. (2010). Researching K-12 online learning: What do we know and what should we examine? Distance Learning, 7(2), 7-12.

Barbour, M. K., Siko, J., Gross, E., \& Waddell, K. (2013). Virtually unprepared: Examining the preparation of K-12 online teachers. In R. Hartshorne, T. L. Heafner, \& T. M. Petty, (Eds.), Teacher education programs and online learning tools: Innovations in teacher preparation (pp. 120-143). Hershey, PA: IGI Global.

Chen, Y., Chen, N.-S., \& Tsai, C.-C. (2009). The use of online synchronous discussion for webbased professional development for teachers. Computers \& Education, 53(4), 1155-1166.

Clary, R. M., \& Wandersee, J. H. (2009). Can teachers learn in an online environment? KappaDelta Pi Record, 46(1), 34-38.

Duncan-Howell, J. (2010). Teachers making connections: Online communities as a source of professional learning. British Journal of Educational Technology, 41(2), 324-340.

Garrison, D. R., \& Anderson, T. (2003). E-Learning in the 21st century: A framework for research and practice. London: Routledge/Falmer.

Hawkins, A.; Graham, C. R., \& Barbour, M. K. (2012). Everybody is their own island: Teacher disconnection in a virtual school. The International Review of Research in Open and Distance Learning, 13(2), 123-144.

Holmes, A., Signer, B., \& MacLeod, A. (2010). Professional development at a distance: A mixed-methods study exploring inservice teachers' views on presence online. Journal of Digital Learning in Teacher Education, 27(2), 76-85.

Journell, W., Beeson, M. W., Crave, J. J., Gomez, M., Linton, J. N., \& Taylor, M. O. (2013). Training teachers for virtual classrooms: A description of an experimental course in online pedagogy. In R. Hartshorne, T. L. Heafner, \& T. M. Petty, (Eds.), Teacher education programs and online learning tools: Innovations in teacher preparation (pp. 120-143). Hershey, PA: IGI Global.

Learn NC. (2008). Training teachers to teach online: The importance of certification for online instructors [White paper]. Retrieved May 15, 2013, from: http://www.learnnc.org/lp/media/uploads/2008/11/colt_white_paper.pdf

Lock, J. (2006). A new image: Online communities to facilitate teacher professional development. Journal of Technology and Teacher Education, 14(4), 663-678.

Marek, K. (2009). Learning to teach online: Creating a culture of support for faculty. Journal of Education for Library and Information Science, 50(4), 275-292. 
National Education Association (NEA). (2006). Guide to teaching online courses. Retrieved from http://www.nea.org/assets/docs/onlineteachguide.pdf

Palloff, R. M., \& Pratt, K. (2011). The excellent online instructor: Strategies for professional development. San Francisco: Jossey-Bass.

Parr, J., \& Ward, L. (2006). Building on foundations: Creating an online community. Journal of Technology and Teacher Education, 14(4), 775-793.

Ray, J. (2009). Faculty perspective: Training and course development for the online classroom. Journal of Online Learning and Teaching, 5(2), 263-276.

Redmond, P. (2011). From face-to-face teaching to online teaching: Pedagogical transitions. Paper presented at Ascilite 2011, Hobart, Tasmania, Australia. Retrieved from http://www.ascilite.org.au/conferences/hobart11/downloads/papers/Redmond-full.pdf

Richards, L. (1999). Using NVivo in qualitative research. Thousand Oaks: Sage.

Rovai, A. (2001). Building community at a distance: A case study. Educational Technology Research and Development, 49(4), 33-48.

Schlager, M. S., \& Fusco, J. (2003). Teacher professional development, technology, and communities of practice: Are we putting the cart before the horse? The Information Society, 19(3), 203-220.

Signer, B. (2008). Online professional development: Combining best practices from teacher, technology and distance education. Journal of In-service Education, 34(2), 205-218.

So, H.-J., Lossman, H., Lim, W.-Y., \& Jacobson, M. J. (2009). Designing an online video based platform for teacher learning in Singapore. Australasian Journal of Educational Technology,25(3), 440-457.

Terosky, A., \& Heasley, C. (2015). Supporting online faculty through a sense of community and collegiality. Online Learning Journal, 19(3), 147-161.

Truman, B. E. (2004). UCF's exemplary faculty support: An institutionalized ecosystem. Journal of Asynchronous Learning, 8(3), 89-96.

Tsai, I.-C., Laffey, J. M., \& Hanuscin, D. (2010). Effectiveness of an online community of practice for learning to teach elementary science. Journal of Educational Computing Research, 43(2), 225-258.

Waltonen-Moore, S., Stuart, D., Newton, E., Oswald, R., \& Varonis, E. (2006). From virtual strangers to a cohesive online learning community: The evolution of online group development in a professional development course. Journal of Technology and Teacher Education, 14(2), 287-311. 
Wenger, E. (1998). Communities of practice: Learning, meaning, and identity.

Cambridge: Cambridge University Press.

Wenger, E., McDermott, R., \& Snyder, W. M. (2002). Cultivating communities of practice: A guide to managing knowledge. Boston, MA: Harvard Business School Publishing.

Williams, L. A., Atkinson, L. C., Cate, J. M., \& O’Hair, M. J. (2008). Mutual support between learning community development and technology integration: Impact on school practices and student achievement. Theory into Practice, 47(4), 294-302.

Yeh, Y.-C. (2010a). Analyzing online behaviors, roles, \& learning communities via online discussions. Educational Technology and Society, 13(1), 140-151.

Yeh, Y.-C. (2010b). Integrating collaborative PBL with blended learning to explore preservice teachers' development of online learning communities. Teaching and Teacher Education, 26(8), 1630-1640. 